\title{
Sainte-Marie-du-Mont, Chapareillan
}

Structures des Hauts de Chartreuse

\section{Alexandre Morin}

\section{(2) OpenEdition}

Édition électronique

URL : http://journals.openedition.org/adlfi/6833

ISSN : 2114-0502

Éditeur

Ministère de la culture

Référence électronique

Alexandre Morin, «Sainte-Marie-du-Mont, Chapareillan », ADLFI. Archéologie de la France - Informations [En ligne], Rhône-Alpes, mis en ligne le 01 mars 2007, consulté le 01 mai 2019. URL : http:// journals.openedition.org/adlfi/6833

Ce document a été généré automatiquement le 1 mai 2019.

(c) Ministère de la Culture et de la Communication, CNRS 


\title{
Sainte-Marie-du-Mont, Chapareillan
}

\author{
Structures des Hauts de Chartreuse
}

\section{Alexandre Morin}

Identifiant de l'opération archéologique : 229396

Date de l'opération : 2007 (PT)

Inventeur(s) : Carron Pierre-Yves (COL)

1 Une opération de prospection sur les structures pastorales (Fig. $\mathrm{n}^{\circ} 1$ : Plan d'ensemble des structures pastorales des Haberts de Barraux, alpage de l'Alpe) s'est déroulée sur les Hauts de Chartreuse, sur les alpages de l'Alpe, du Pinet et de l'Alpette (Sainte-Marie-duMont et Chapareillan, Isère), avec les soutiens financiers de la réserve naturelle des Hauts de Chartreuse et du Conseil général de l'Isère. Un bilan sur les sources écrites pour la période médiévale a été pris en charge par Sylvain Excoffon et Fabrice Mouthon. La synthèse est en cours. Le travail de terrain a consisté en un premier inventaire diachronique des structures (recherche, pointage, fiche descriptive, plan, cliché). Au terme de l'opération, quarante cinq structures ont été inventoriées sur les trois alpages.

2 L'habitat du berger, appelé localement habert, est représenté par de simples cabanes ou par des structures plus complexes, pouvant correspondre à de véritables chalets d'alpage liés à l'exploitation laitière (fabrication du fromage). Pour le parcage du bétail, on note la présence de simples enclos jusqu'à de véritables étables ou bergeries, dénommées halles ou écuries. Pour certains enclos et cabanes, les bergers ont utilisé des éléments naturels, comme les abris sous roche ou sous bloc, les grottes et même des dolines pour le parcage et le tri des brebis. Des relevés des Haberts de Barraux, secteur qui réunit une forte concentration de structures, ont été réalisés par Pierre-Yves Carron: plusieurs relevés pierre à pierre, un relevé topographique et un plan d'ensemble ont été effectués. Toujours aux Haberts de Barraux, les prospections ont permis d'identifier, dans un banc rocheux, la présence d'un grand front d'extraction de près d'une centaine de mètres de longueur pour deux à quatre mètres de hauteur. L'exploitation a fourni des pierres de toutes tailles, jusqu'à des blocs pouvant atteindre un mètre de longueur, ainsi que des 
dallettes équarries. Cette carrière semble clairement liée à la construction de quatre grandes structures implantées au pied du front d'extraction, correspondant à deux chalets d'alpage (structures 10 et 11) et à deux grandes étables ou bergeries (structures 12 et 13).

\section{ANNEXES}

Fig. $\mathrm{n}^{\circ} 1$ : Plan d'ensemble des structures pastorales des Haberts de Barraux, alpage de l'Alpe

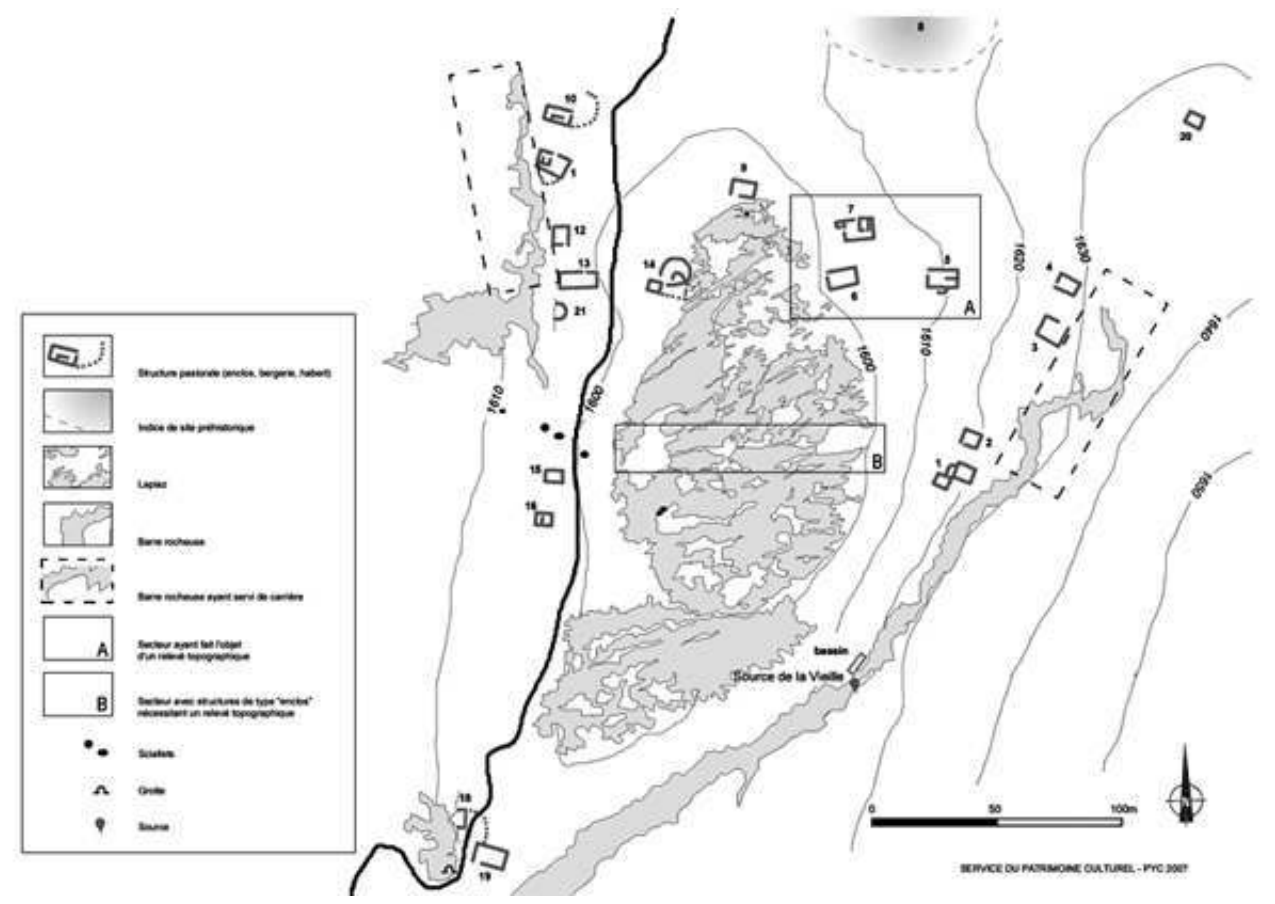

Auteur(s) : Carron, Pierre-Yves. Crédits : ADLFI (2007)

INDEX

Index chronologique : Moyen Âge*

Index géographique : Rhône-Alpes, Isère (38), Sainte-Marie-du-Mont operation Prospection thématique (PRT)

\section{AUTEURS}

\section{ALEXANDRE MORIN}

BEN 